\title{
Syntheses of Poly(ethylene oxide) Polyurethane Ionomers
}

\author{
XINLING WANG, ${ }^{1}$ LEI WANG, ${ }^{1}$ HUI LI, ${ }^{1}$ XIAOZHEN TANG, ${ }^{1}$ FENG-CHIH CHANG ${ }^{2}$ \\ ${ }^{1}$ School of Chemistry and Chemical Technology, Shanghai Jiaotong University, \\ Shanghai 200030, People's Republic of China \\ ${ }^{2}$ Department of Applied Chemistry, National Chiao-Tung University, Hsin-Chu, Taiwan
}

Received 24 June 1999; accepted 10 October 1999

\begin{abstract}
Sulfonated dimethyl fumarate (SDMF) was prepared with dimethyl fumarate $(\mathrm{DMF})$ and sodium hydrogensulfite $\left(\mathrm{NaHSO}_{3}\right)$. Sodium sulfonate side-chain poly(ethylene oxide) (SPEO) was synthesized by grafting sodium sulfonate onto the chain of PEO with molecular weights of $400,600,800$, and 1000 . SPEO was used subsequently in step-growth polymerization to give a polyurethane ionomer (SPU). Samples were characterized by element analysis, FTIR, ${ }^{1} \mathrm{H}-\mathrm{NMR}$, EDX mapping, X-ray, gel permeation chromatography, and impedance analysis. The SPUs exhibited an amorphous structure. The maximum conductivity of the SPU was $1.02 \times 10^{-6} \mathrm{~S} \mathrm{~cm}^{-1}$ at the room temperature. () 2000 John Wiley \& Sons, Inc. J Appl Polym Sci 77: 184-188, 2000
\end{abstract}

Key words: polyurethane ionomer; poly(ethylene oxide); electrolyte

\section{INTRODUCTION}

Various types of polyurethanes have been used as solid polymer electrolytes because of their good chemical stability, excellent mechanical properties, and low glass transition temperature $\left(T_{g}\right)$. Consequently, growing attention has been paid to the synthesis of polyurethanes containing ionic groups, called polyurethane ionomers. ${ }^{1-4}$ Most of the studies on the synthesis of polyurethane ionomers used in polymer electrolytes involve the use of a hard-segment chain extender containing a tertiary nitrogen atom capable of quaterization after polymerization. ${ }^{5}$ This method has limited application, however, and there is a need for the development of new syntheses of polyurethane ionomers. In this article, we synthesized and characterized a new ionic sulfonated dimethyl fumarate (SDMF), a sodium sulfonate side-chain poly(ethylene oxide) (SPEO), and polyurethane ionomers (SPUs).

Correspondence to: $\mathrm{X}$. Wang.

Journal of Applied Polymer Science, Vol. 77, 184-188 (2000)

() 2000 John Wiley \& Sons, Inc.

\section{EXPERIMENTAL}

\section{Purification of Solvents and Reagents}

Poly(ethylene oxide)s (PEOs) with different molecular weights of 400,600, 800, and 1000 from the Aldrich Chemical Co. were dried under a vacuum at $60^{\circ} \mathrm{C}$ for $48 \mathrm{~h}$ before use. 4,4'-Methylenebis(phenyl isocyanate) (MDI), also from Aldrich, was distilled under a vacuum and used immediately. $N, N$-Dimethylacetamide (DMA) and 1,4-butanediol (BDOL) from Riedel-de Haën were dried by refluxing over $\mathrm{CaH}$ for $4 \mathrm{~h}$ to exclude trace water and then distilled under a vacuum. Sodium hydrogensulfite $\left(\mathrm{NaHSO}_{3}\right)$, dimethyl sulfoxide (DMSO), and calcium hydride, from $\mathrm{Al}$ drich, were used without further purification.

\section{Synthesis of SDMF}

SDMF was prepared by dissolving DMF and $\mathrm{NaHSO}_{3}$ in a methanol and water solution and

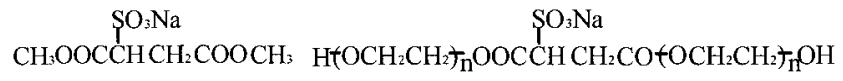
SDMF

(SPEO)

Scheme 1 


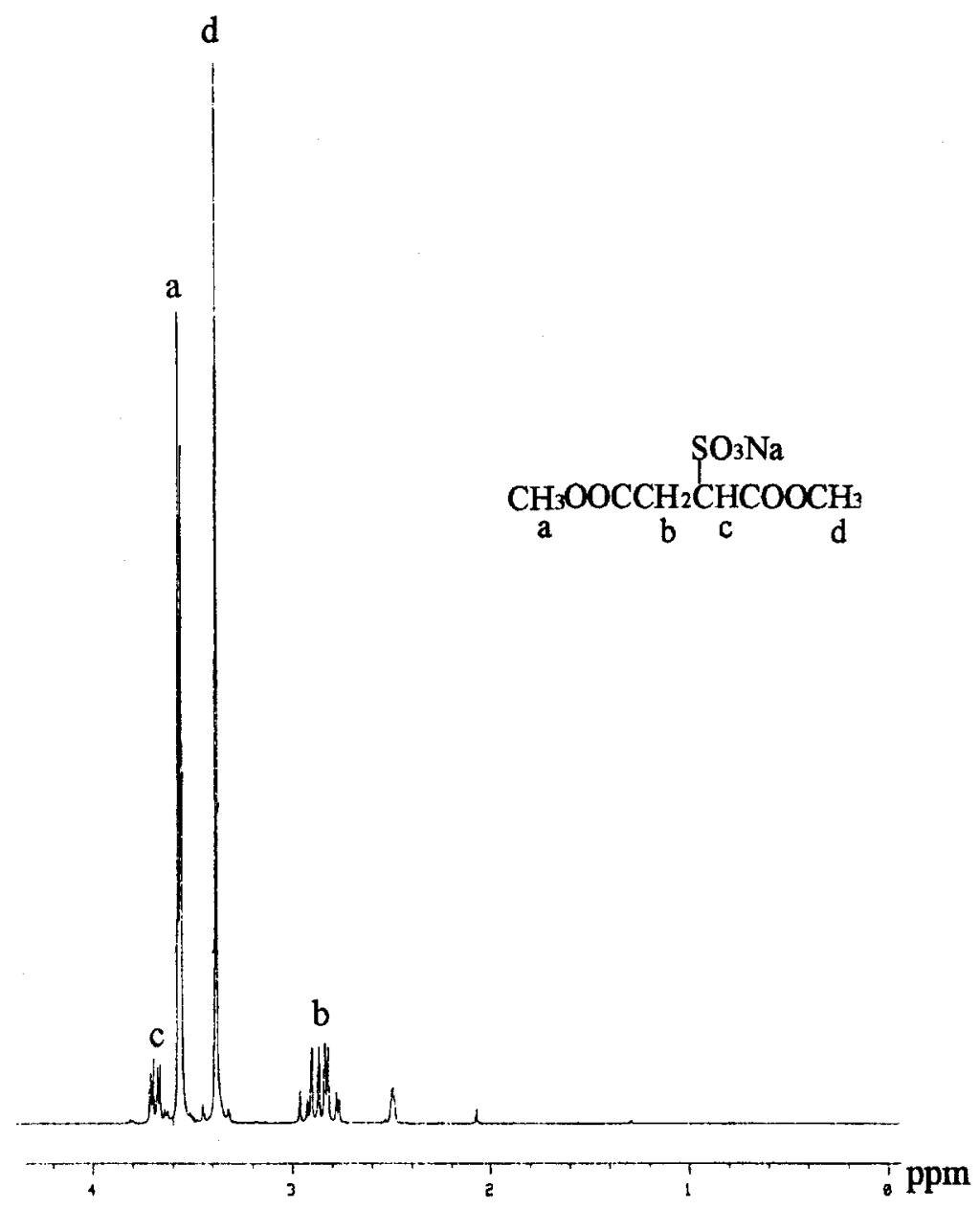

Figure $1{ }^{1} \mathrm{H}-\mathrm{NMR}$ spectrum of SDMF in SMSO- $d_{6}$ at $25^{\circ} \mathrm{C}$.

refluxing at $80^{\circ} \mathrm{C}$ for $8 \mathrm{~h}$. The solvent was removed under a vacuum. The product was extracted by DMSO, precipitated by a large amount of acetone, and dried under a vacuum at $60^{\circ} \mathrm{C}$ for $24 \mathrm{~h}$. The molecular structure of SDMF is shown in Scheme 1 (yield $\approx 70 \%$ ).

Table I Analysis Results of Samples

\begin{tabular}{|c|c|c|c|c|c|c|c|c|c|}
\hline \multirow{3}{*}{$\begin{array}{l}\text { Sample } \\
\text { SDMF }\end{array}$} & \multicolumn{6}{|c|}{ Element Analysis } & \multirow[b]{2}{*}{$\mathrm{MW}\left(\times 10^{3}\right)$} & \multirow[b]{2}{*}{$\mathrm{Tg}(\mathrm{K})$} & \multirow[b]{2}{*}{$\sigma^{\mathrm{a}}\left(\mathrm{S} \mathrm{cm}^{-1}\right)$} \\
\hline & \multicolumn{2}{|c|}{$\mathrm{C} \%$} & \multicolumn{2}{|c|}{$\mathrm{H} \%$} & \multicolumn{2}{|c|}{$\mathrm{S} \%$} & & & \\
\hline & $29.0^{\mathrm{b}}$ & $28.6^{\mathrm{c}}$ & $3.69^{b}$ & $3.54^{\mathrm{c}}$ & $12.9^{\mathrm{b}}$ & $13.3^{\mathrm{c}}$ & - & - & - \\
\hline SPEO400 & 47.0 & 46.2 & 7.52 & 7.31 & 3.36 & 3.46 & 1.1 & - & - \\
\hline SPEO600 & 49.2 & 49.0 & 7.90 & 8.60 & 2.37 & 1.95 & 1.2 & - & - \\
\hline SPEO1000 & 51.3 & 50.8 & 8.30 & 8.11 & 1.47 & 1.33 & 1.9 & - & - \\
\hline SPU400 & 57.6 & 56.0 & 6.41 & 6.19 & 1.67 & 1.76 & 20.8 & 278.8 & $2.24 \times 10^{-8}$ \\
\hline SPU600 & 57.1 & 55.7 & 6.66 & 6.40 & 1.44 & 1.61 & 15.2 & 265.9 & $2.27 \times 10^{-7}$ \\
\hline SPU1000 & 56.4 & 54.9 & 7.43 & 7.25 & 1.03 & 1.30 & 9.4 & 243.1 & $1.02 \times 10^{-6}$ \\
\hline
\end{tabular}

${ }^{\text {a }}$ At room temperature.

b Theory.

${ }^{\mathrm{c}}$ Measured.

${ }^{\mathrm{d}}$ SPEO400 indicates PEO of molecular weight 400. 


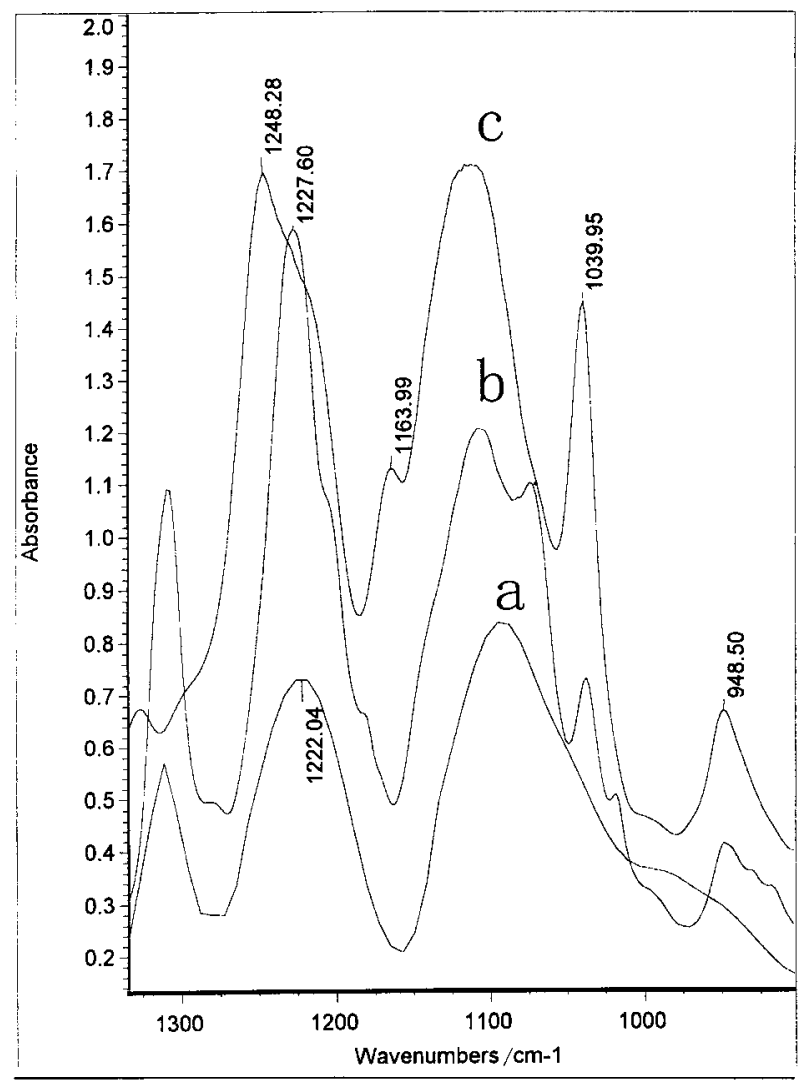

Figure 2 IR spectra of (a) PU, (b) SPU400, and (c) SPEO.

\section{Synthesis of SPEO}

SPEO was prepared by mixing SDMF, PEO, and the catalyst under a nitrogen atmosphere at $175^{\circ} \mathrm{C}$ for $5 \mathrm{~h}$. SPEO was solubilized in acetone and the precipitate was subsequently filtered. SPEO was dried under a vacuum at $60^{\circ} \mathrm{C}$ for $24 \mathrm{~h}$ after the acetone was removed by distillation. The molecular structure of SPEO is shown in Scheme 1.

\section{Synthesis of SPUs}

In preparing the SPUs, a DMA solution containing SPEO was added dropwise to a DMA solution containing MDI under a nitrogen atmosphere at $40^{\circ} \mathrm{C}$ for $3 \mathrm{~h}$. Subsequently, the DMA solution containing BDOL was added dropwise over a period of $30 \mathrm{~min}$ and continually reacted for $1.5 \mathrm{~h}$. The polymer formed was precipitated and recovered in a large amount of acetone and then immersed in ethanol for $24 \mathrm{~h}$. The polymer was filtered and dried under a vacuum at $60^{\circ} \mathrm{C}$ for $24 \mathrm{~h}$.

\section{RESULTS AND DISCUSSION}

The structure of SDMF was characterized by a ${ }^{1} \mathrm{H}-\mathrm{NMR}$ spectrum. Figure 1 shows the chemical

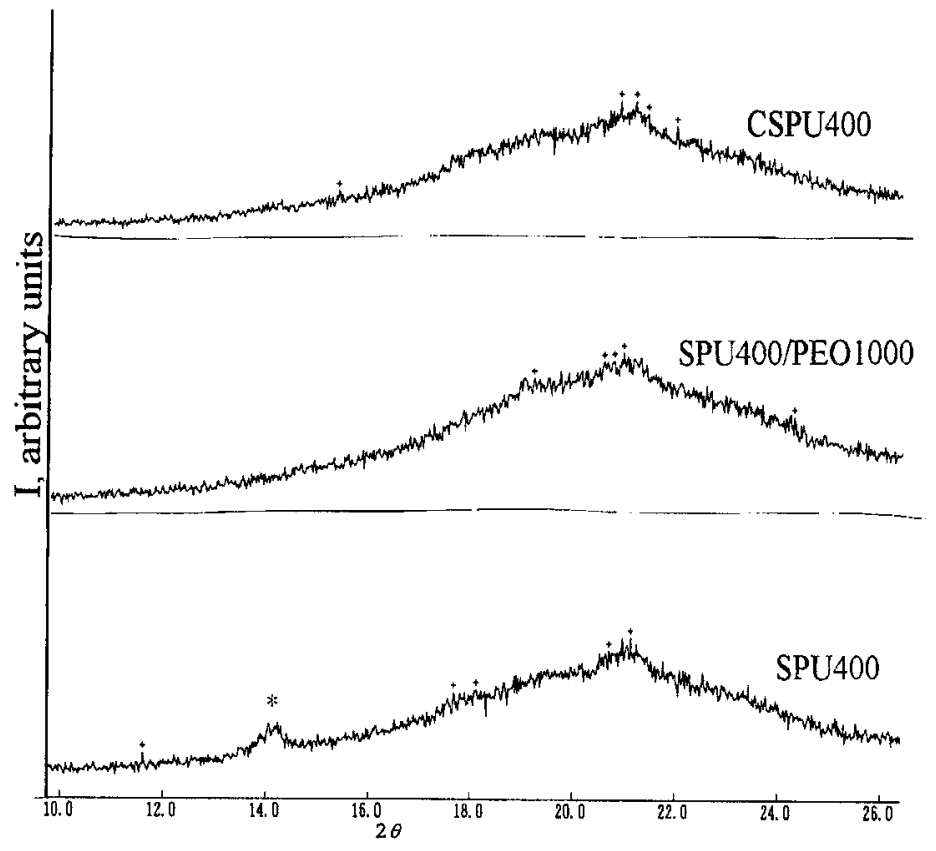

Figure 3 X-ray spectra of SPU400, SPU400/PEO1000, and CSPU400. 


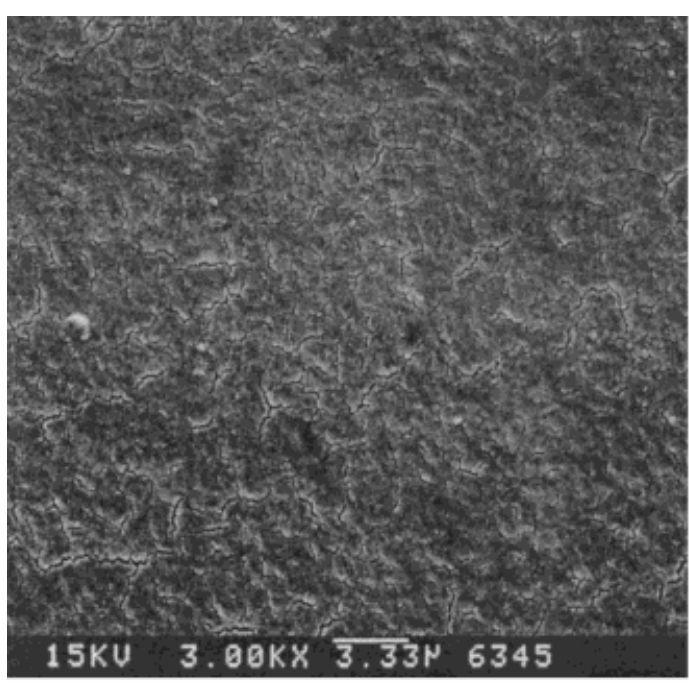

(a)

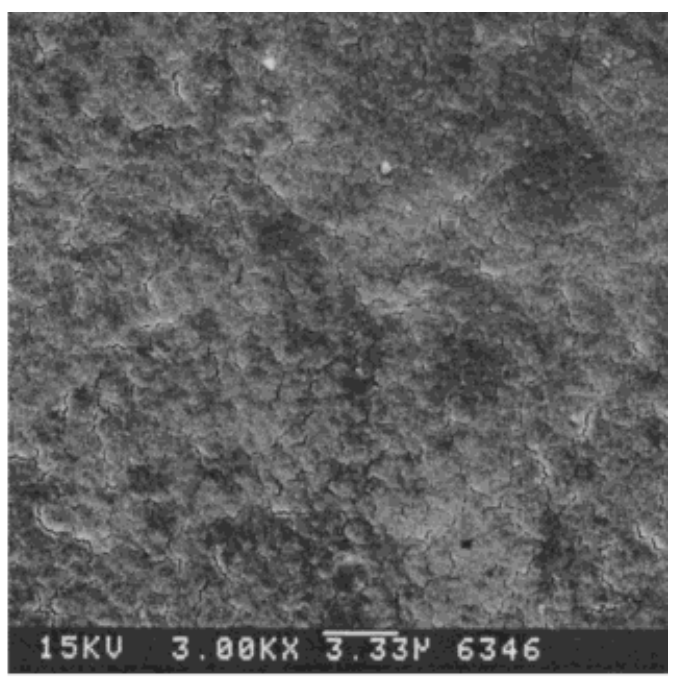

(b)

Figure 4 SEM photos of (a) SPU400 and (b) SPU1000.

shifts of four kinds of protons at 2.86, 3.38, 3.56, and $3.68 \mathrm{ppm}$, respectively. The ratio is approximately $3: 2: 1: 3$, which is consistent with the expected SDMF structure. The solvent induced two small peaks of chemical shifts at 2.1 and $2.5 \mathrm{ppm}$.

The element analyses of SDMF, SPEO, and SPU are summarized in Table I, indicating high purity, in general, in these samples. The IR spectra (Fig. 2) of the SPU shows the following characteristic bands: $\mathrm{S}-\mathrm{O}$ stretching at 1039 and $1163 \mathrm{~cm}^{-1}$ and $\mathrm{C}-\mathrm{O}-\mathrm{C}$ stretching at 1100 and $1222 \mathrm{~cm}^{-1}$.

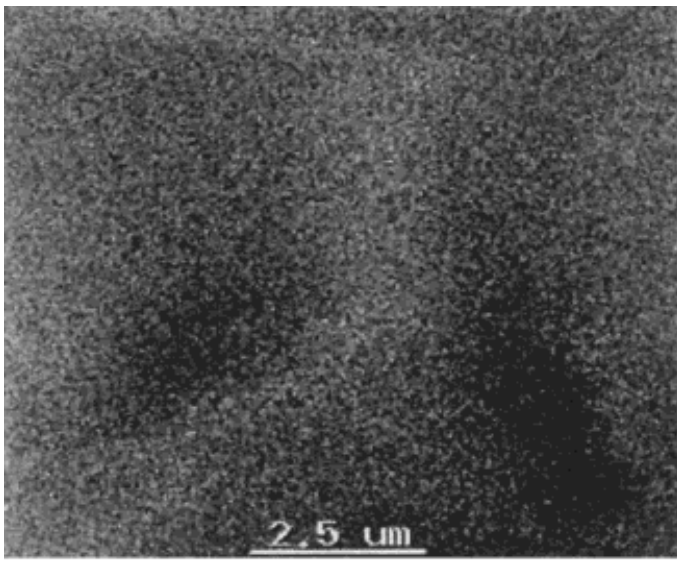

(a)
The DSC data and the conductivity for the SPUs are listed in Table I. The glass transition temperature $\left(T_{g}\right)$ of the SPUs decreased but the conductivity increased with increase of the molecular weight of PEO. The conductivity of SPU1000 was $1.02 \times 10^{-6} \mathrm{~S} \mathrm{~cm}^{-1}$.

Figure 3 shows the X-ray spectra of SPU. A broad weak refraction near $2 \theta=21^{\circ}$ was observed, which shows that the SPUs exhibit an amorphous structure that is of advantage to enhance the SPU conductivity. A typical scanning electronic micrograph (SEM) of the surface of the

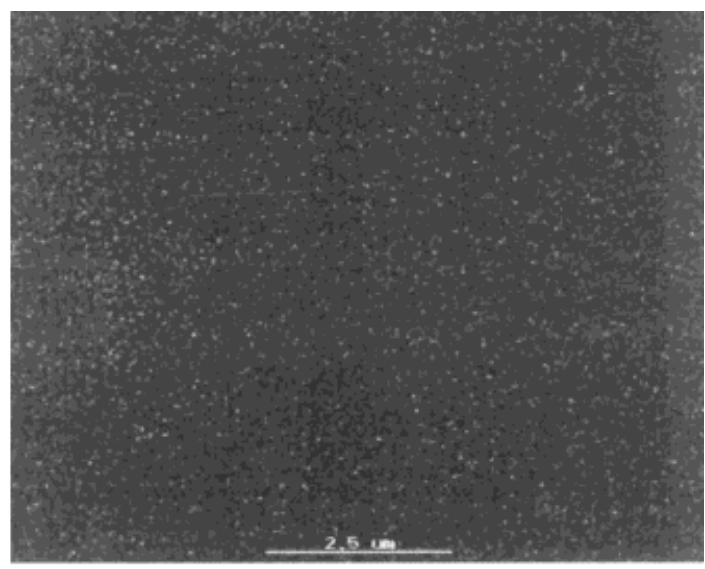

(b)

Figure 5 EDX elemental mapping images of the sulfur of (a) SPU400 and (b) SPU1000. 


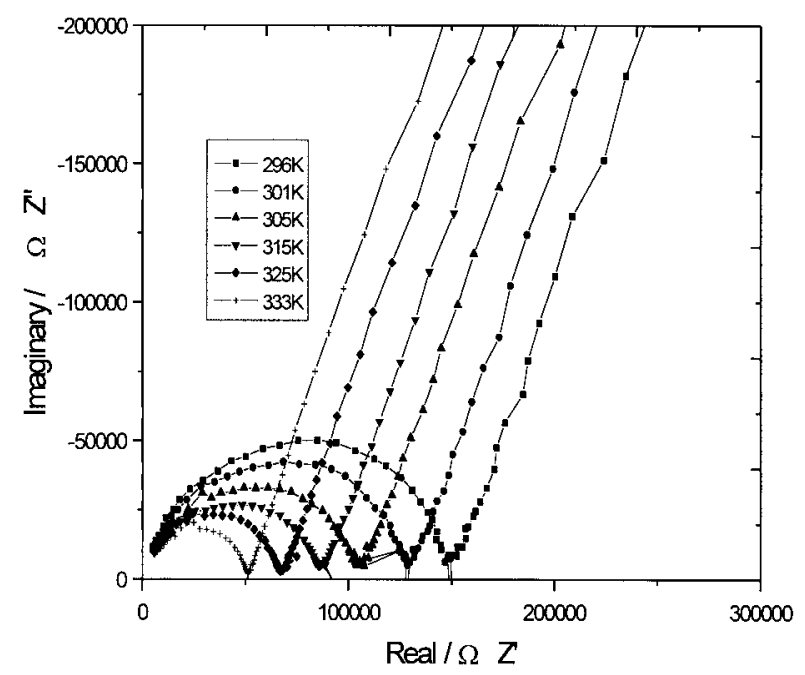

Figure 6 Cole-Cole plots of CSPU4000/PEODM at different temperatures.

SPUs with varied molecular weights of PEO is shown in Figure 4. Figure 4 indicates that the morphology of the SPUs is not different. It is possible that the sodium ions in the SPUs are able to improve their compatibility. EDX mapping (Fig. 5) shows that the sulfur atoms are distributed homogeneously in the SPU. This result is in agreement with the X-ray and SEM analyses.

The typical complex impedance spectra for the SPU sandwiched between stainless-steel electrodes are shown in Figure 6. A high-frequency semicircle arc and a low-frequency sharp slope under different temperatures are seen in the spectra. The SPU conductivity was calculated from Cole-Cole plots.

As shown in Table II, SPU600, 800, and 1000 were fully soluble in water without a solid resi-
Table II Solubility of SPU in Water

\begin{tabular}{lll}
\hline Sample & Solubility & Appearance \\
\hline SPU400 & Soluble & Stable emulsion \\
SPU600 & Soluble & Stable emulsion \\
SPU800 & Fully soluble & Homogeneous solution \\
SPU1000 & Fully soluble & Homogeneous solution \\
\hline
\end{tabular}

due. The solution of SPU400 in water is an emulsion. This observation is in marked contrast to the nonionomer which is quite insoluble in water.

\section{CONCLUSIONS}

SDMF, SPEO, and SPUs were synthesized and characterized. The structure of SDMF and SPEO are consistent with the expected structure. The resulting polyurethane was easily soluble in water and the solution showed high stability. The conductivity of SPU1000 was $1.02 \times 10^{-6} \mathrm{~S} \mathrm{~cm}^{-1}$ at the room temperature.

\section{REFERENCES}

1. Huang, F.; Wang, X.; Li, S. J Macromol Sci Chem A 1991, 28, 175.

2. Yang, C. Z.; Hwang, K. K. S.; Cooper, S. L. Macromol Chem 1983, 184, 651.

3. Wang, L.; Yang, B.; Wang, X. L.; Tang, X. Z. J Appl Polym Sci 1999, 71, 1711.

4. Miller, J. A.; Hwang, K. K. S.; Yang, C. Z.; Cooper, S. L. J Elast Plast 1983, 15, 174.

5. Abraham, K. M.; Jiang, Z.; Carroll, B. Chem Mater 1997, 9, 1978. 